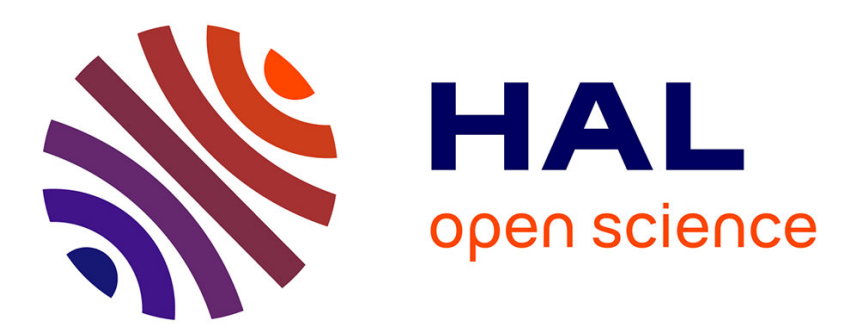

\title{
Phosphorylated microcapsules containing natural oil for potential self-healing use
}

\author{
Ayoub Ouarga, Hassan Noukrati, Itziar Iraola-Arregui, Allal Barroug,
} Abdelhamid Elaissari, Hicham Ben Youcef

\section{- To cite this version:}

Ayoub Ouarga, Hassan Noukrati, Itziar Iraola-Arregui, Allal Barroug, Abdelhamid Elaissari, et al.. Phosphorylated microcapsules containing natural oil for potential self-healing use. Materials Today: Proceedings, 2022, in press. 10.1016/j.matpr.2021.05.093 . hal-03244215

\section{HAL Id: hal-03244215 https://hal.science/hal-03244215}

Submitted on 1 Jun 2021

HAL is a multi-disciplinary open access archive for the deposit and dissemination of scientific research documents, whether they are published or not. The documents may come from teaching and research institutions in France or abroad, or from public or private research centers.
L'archive ouverte pluridisciplinaire HAL, est destinée au dépôt et à la diffusion de documents scientifiques de niveau recherche, publiés ou non, émanant des établissements d'enseignement et de recherche français ou étrangers, des laboratoires publics ou privés. 


\title{
Phosphorylated microcapsules containing natural oil for potential self-healing use: a comparative study
}

\author{
Ayoub Ouarga ${ }^{\mathrm{a}, \mathrm{b}, \mathrm{c}}$, Hassan Noukratid ${ }^{\mathrm{d}}$, Itziar Iraola-Arregui ${ }^{\mathrm{a}}$, Allal Barroug ${ }^{\mathrm{b}, \mathrm{d}}$, Abdelhamid \\ Elaissaric ${ }^{\mathrm{c}}$ Hicham Ben youcef ${ }^{\mathrm{a}}$ \\ ${ }^{a}$ Mohammed VI Polytechnic University (UM6P), HTMR-Lab, Lot 660 - Hay Moulay Rachid, 43150, Benguerir, Morocco \\ ${ }^{b}$ Cadi Ayyad University, FSSM, BP. 2390, 40000 Marrakech, Morocco \\ ${ }^{\mathrm{c}}$ Univ Lyon, University Claude Bernard Lyon-1, CNRS, ISA-UMR 5280, 69622 Villeurbanne, FRANCE \\ ${ }^{d}$ Mohammed VI Polytechnic University (UM6P), CIAM, Lot 660 - Hay Moulay Rachid, 43150, Benguerir, Morocco
}

\begin{abstract}
This work reports the preparation of oil-filled microcapsules for self-healing purpose. Biopolymeric microcapsules loaded with vegetable oils as green corrosion inhibitors were formulated using ethyl cellulose and phosphorylated ethyl cellulose as encapsulating materials. Chemical structure, thermal stability and surface morphology of microcapsules were characterized by Fourier transform infrared (FTIR) spectroscopy, thermal gravimetric analysis (TGA) and scanning electron microscopy (SEM), FTIR and TGA analysis confirmed the presence of oil core and polymer shell in the formulated microcapsules. The scanning electron microscopy was used to study the shape and morphology of the prepared microcapsule. The obtained results revealed the spherical-like shape of the obtained capsules with diameters ranging from 10 up to $170 \mu \mathrm{m}$. Thus, the current study shows the potential application of phosphorylated ethyl cellulose for the development of new environmentally friendly microcontainers bearing corrosion inhibitors.
\end{abstract}

Keywords: Microencapsulation; Phosphorylation; Ethyl cellulose; Self-healing; Anti-corrosion coating; Core-Shell microcapsule.

\section{Introduction}

Over the last decade, the study and development of integrated chemical structures have attracted the attention of researchers. One of these structures are microcapsules made using different microencapsulation techniques. The main objective of preparing capsules is to envelope core material by a shell material in order to be protected from the surrounding environment. Compounds storage and the possibility of controlling the release of the core material have made the use of microcapsules possible in different commercial applications, such as drug delivery systems, food preservatives, electronic devices, cosmetic products, and self-healing materials. [1]-[4]

Within various techniques of self-healing materials development, the extrinsic method based on encapsulation strategy is the most considered approach. It is based on the encapsulation of a healing agent in a polymeric shell material. Then capsules have to be embedded into a matrix material allowing their release during a rupture event and therefore promoting self-healing. [5]

Corrosion inhibitors-loaded microcapsules for the application in self-healing coatings were the main objective of various studies. This application was based on the concept of extrinsic self-healing system firstly initiated by White et al. in 2001.[6] Conceptually, a self-healing anticorrosion coating is considered as a combination of the passive component, represented by the conventional matrix coating, and the active component represented by the corrosion inhibitor-containing micro/nano capsule. This concept has been used in different studies to develop anticorrosion coatings. For instance, linseed and tung oils were mainly encapsulated using urea-formaldehyde as the shell material, and the prepared microcapsules were incorporated into epoxy-based coatings in order to study and understand their effect on corrosion inhibition and healing performance. [7], [8] 
In this study, various oil-filled microcapsules were prepared via solvent evaporation method. Ethyl cellulose and phosphorylated ethyl cellulose were used as polymeric shell materials to encapsulate Lavender oil (LO), black seed oil (BSO), prickly pear oil (PPO) and argan oil (AO). The prepared microcapsules were characterized and the effect of phosphorylated shell on the microcapsules properties has been discussed. The obtained microcapsules are destined to be used in our upcoming work to develop anti-corrosion self-healing coatings, but, can be explored in additional key applications (e.g., biomaterials). [9]

\section{Experimental}

\subsection{Materials}

Ethyl cellulose (EC) powder, sodium dodecyl sulfate (SDS) and urea powder were purchased from Sigma Aldrich. Orthophosphoric acid (85\%) and methanol were obtained from Merck KGaA. The ethyl acetate (EA) was supplied by Somaprol, and Sodium hydroxide was provided by VWR. Lavender oil (LO), black seed oil (BSO), prickly pear oil (PPO) and argan oil (AO) were purchased from a drugstore in order to be used as core materials for microcapsules. All chemicals were analytical reagents grade and were used without any further purification.

\subsection{Preparation of microcapsules}

Oil-filled microcapsules were prepared using a two stages solvent evaporation method as described elsewhere. [10], [11] Both, ethyl cellulose (EC) and phosphorylated ethyl cellulose (P-EC) where used as shell materials for the microcapsule's preparation (Schema 1). EC powder or P-EC powder were dissolved in ethyl acetate for 2 hours under room temperature and under magnetic stirring at $650 \mathrm{rpm}$. The oil was then added to the solution stirring for 30 minutes more. In parallel, a 1wt.\% sodium dodecyl sulfate aqueous solution was prepared. The polymeric solution (oil phase) was then added dropwise to the aqueous solution (water phase) under continuous mechanical mixing at a temperature of $60^{\circ} \mathrm{C}$ for 90 minutes. The obtained mixture was freeze-dried and rinsed with distilled water then filtered and dried to generate the final native microcapsules $(\mathrm{MC})$ and phosphorylated-microcapsules (P-MC).

To investigate the effect of shell materials and different oils on the microencapsulation process, the preparation was conducted using EC and P-EC as shell materials and LO, BSO, PPO and AO as core materials (Scheme 1).

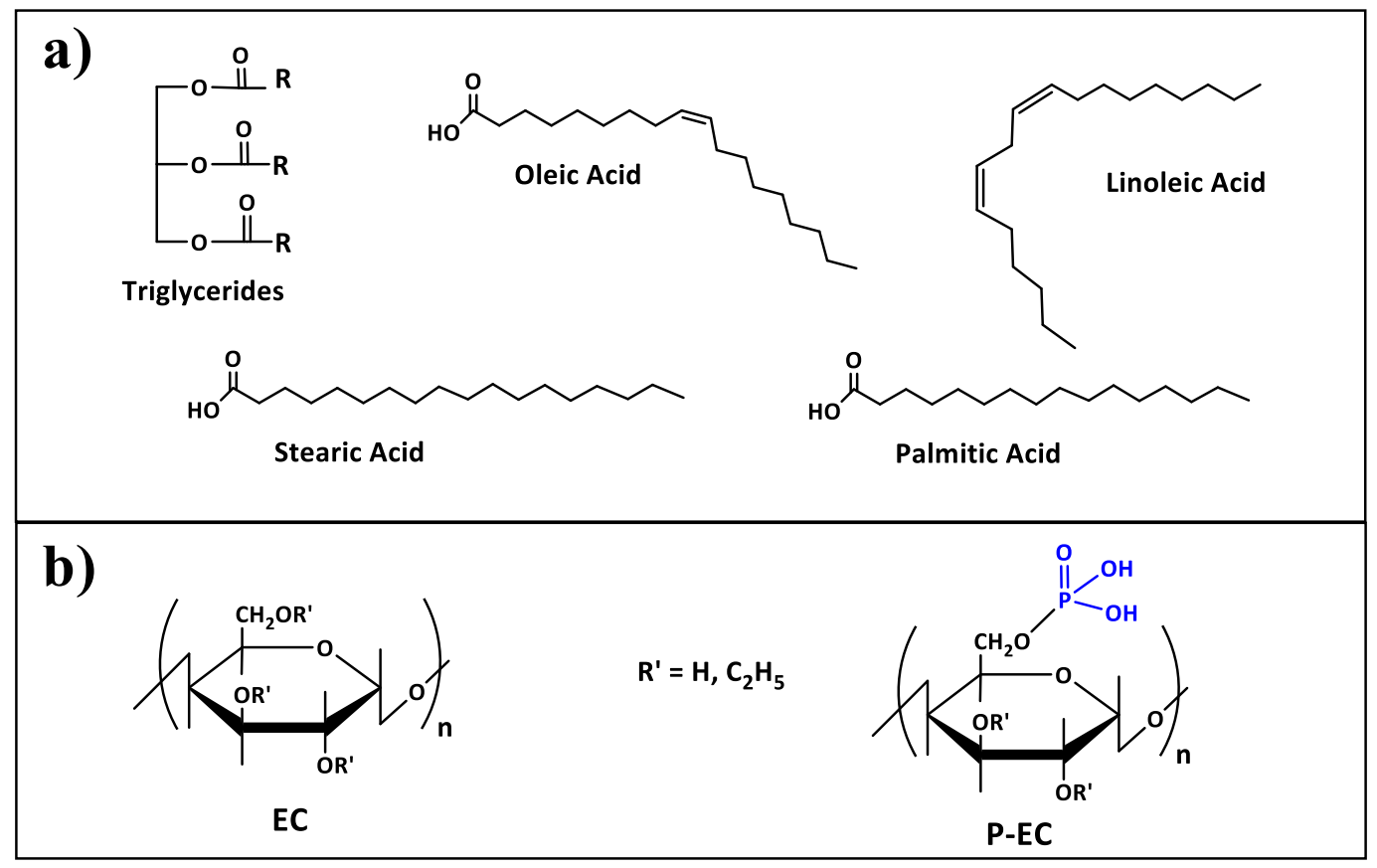

Scheme. 1. (a) Structure of major components in different vegetable oils (Lavender oil, Prickly pear oil, Black seed oil and Argan oil). (b) Structure of Ethyl cellulose (EC) and phosphorylated ethyl cellulose (P-EC). 


\subsection{Characterization}

Fourier Transform Infrared (FTIR) analysis was performed for initial raw materials, phosphorylated ethyl cellulose and prepared microcapsules in order to identify the core and shell materials. The FTIR spectra were recorded by a PerkinElmer FTIR spectrophotometer (Wellesley, MA, United States) using attenuated total reflection (ATR) technique and collecting 16 scans in the $4000-600 \mathrm{~cm}^{-1}$ range with a resolution of $4 \mathrm{~cm}^{-1}$.

Thermogravimetric analysis (TGA) was carried out using a thermogravimetric analyzer (Model -TGA 5500, Discovery series, TA Instruments, United States) to evaluate the thermal stability of initial raw materials, phosphorylated ethyl cellulose and the prepared oil-filled microcapsules. The analysis was performed under a nitrogen atmosphere with a heating rate of $10{ }^{\circ} \mathrm{C} / \mathrm{min}$ from room temperature up to $700^{\circ} \mathrm{C}$.

The surface morphology and the shape of prepared microcapsules were observed using a scanning electron microscope ((Philips XL 40 ESEM). Before analysis, the microcapsules were coated with gold to improve imaging during electron irradiation.

\section{Results and discussion}

\subsection{Characterization of microcapsules}

Fourier transform infrared (ATR-FTIR) spectroscopy was used to characterize the core materials (LO, BSO, PPO and AO), the shell materials (EC and P-EC) and the prepared oil-filled microcapsules. The FTIR spectra of the core, shell and microcapsules were recorded in frequency range of $4000-600 \mathrm{~cm}^{-1}$ and reported in Fig. 1. The obtained results revealed that the FTIR spectra of microcapsules have been found matching with all the encapsulated oils spectra.

For instance, the FTIR spectra of lavender oil showed sharp peaks at $620 \mathrm{~cm}^{-1}, 730 \mathrm{~cm}^{-1}$ and $893 \mathrm{~cm}^{-1}$ attributed to $\mathrm{C}-\mathrm{H}$ vibrations. The peak at $997 \mathrm{~cm}^{-1}$ was assigned to $-\mathrm{CH}_{2}$ vibrations. The peaks at $1095 \mathrm{~cm}^{-1}, 1163 \mathrm{~cm}^{-1}$ and 1238 $\mathrm{cm}^{-1}$ were related to C-O stretching vibrations. The peaks at $1373 \mathrm{~cm}^{-1}, 1426 \mathrm{~cm}^{-1}$ and $1456 \mathrm{~cm}^{-1}$ belong to C-H bending vibrations. The peak at $1651 \mathrm{~cm}^{-1}$ was due to $\mathrm{C}=\mathrm{C}$ stretching vibrations. The peak at $1748 \mathrm{~cm}^{-1} \mathrm{correspond}^{-1}$ to $\mathrm{C}=\mathrm{O}$ stretching vibrations and the peaks at $2861 \mathrm{~cm}^{-1}, 2921 \mathrm{~cm}^{-1}$ and $3004 \mathrm{~cm}^{-1}$ were associated with the $-\mathrm{CH}_{2}$ stretching, while the band at $3300 \mathrm{~cm}^{-1}$ was ascribed to $-\mathrm{O}-\mathrm{H}$ stretching vibrations. Those values were close to the ones reported in a previous work. [12]

The FTIR spectra of EC showed characteristic peaks at $1056 \mathrm{~cm}^{-1}$ assigned to $-\mathrm{C}-\mathrm{O}-\mathrm{C}-$ stretching vibrations. The peaks at $2878 \mathrm{~cm}^{-1}$ and $2971 \mathrm{~cm}^{-1}$ correspond to $-\mathrm{CH}$ stretching vibrations. The peak at $1373 \mathrm{~cm}^{-1}$ was attributed to $\mathrm{CH}$ bending vibrations and the peak at $3475 \mathrm{~cm}^{-1}$ was associated to -O-H stretching vibrations. [13]

New small peaks appeared in the FTIR spectra of phosphorylated ethyl cellulose as well as phosphorylated microcapsules. The peaks observed at $810 \mathrm{~cm}^{-1}$ and $1630 \mathrm{~cm}^{-1}$ were attributed to $\mathrm{P}-\mathrm{O}-\mathrm{C}$ and $\mathrm{O}=\mathrm{P}-\mathrm{OH}$ groups, respectively. [10] These new peaks appeared thanks to the presence of phosphorus in the P-EC shell material.

The infrared spectra of the microcapsules revealed all the characteristics peaks of the core material and the shell material for all the encapsulated oils using EC or P-EC as shell material (in yellow in Fig. 1), which confirmed clearly that the encapsulation was correctly carried out using different oil core and polymer shell materials. Furthermore, for all prepared microcapsules, no peaks related to the free chemicals used in the encapsulation process have been identified, so the efficiency of the capsule cleaning process has been demonstrated. 

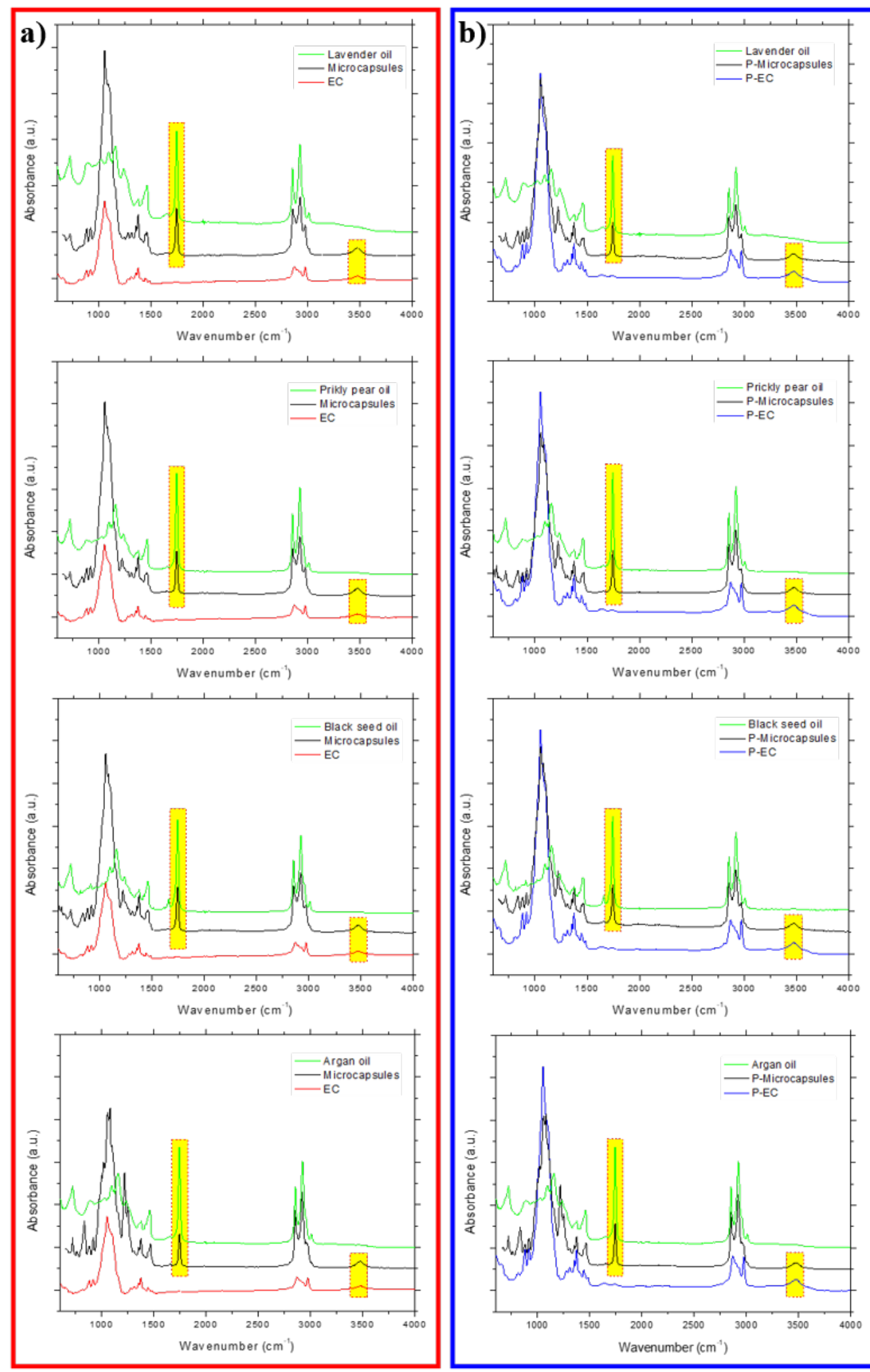

Fig. 1. (a) FTIR spectra of ethyl cellulose (EC), Lavender oil, Prickly pear oil, Black seed oil, Argan oil and the corresponding microcapsules. (b) FTIR spectra of phosphorylated ethyl cellulose (P-EC), Lavender oil, Prickly pear oil, Black seed oil, Argan oil and the corresponding P-Microcapsules. 


\subsection{Microcapsules thermal characteristics and content}

Thermogravimetric analysis (TGA) has been used to investigate the thermal stability of the prepared microcapsules, the encapsulated oils (LO, PPO, BSO, AO) and the shell materials (EC and P-EC). The obtained results are shown in Fig. 2.

The phosphorylated and non-phosphorylated oil-filled microcapsules (MC and P-MC) show two stages of weight loss. For instance, lavender oil microcapsules show two stages at $180-285^{\circ} \mathrm{C}$ and $285-480{ }^{\circ} \mathrm{C}$, corresponding to the decompositions of ethyl cellulose shell and the lavender oil core, respectively. In the case of prickly pear oil microcapsules, the two stages related to the decomposition of EC and PPO were observed at $195-285^{\circ} \mathrm{C}$ and $285-475$ ${ }^{\circ} \mathrm{C}$, respectively. The black seed oil microcapsules and argan oil microcapsules also exhibit two stages of weight loss related to EC and the encapsulated oils (Table 1). The thermogram of the phosphorylated microcapsules filed with lavender oil shows a first stage weight loss at $165-280{ }^{\circ} \mathrm{C}$ related to the decomposition of phosphorylated ethyl cellulose. The second stage of weight loss related to the lavender oil decomposition was observed between $280{ }^{\circ} \mathrm{C}$ and $505{ }^{\circ} \mathrm{C}$. The decomposition of phosphorylated microcapsules containing prickly pear oil was observed through two stages of weight loss at $170-280^{\circ} \mathrm{C}$ and $280-520^{\circ} \mathrm{C}$. The phosphorylated microcapsules containing black seed oil and argan oil shows two stages weight loss as well (Table 1).

Table 1. Thermogravimetric analysis (TGA) results of the prepared microcapsules.

\begin{tabular}{lccccc}
\hline \multirow{2}{*}{ Sample } & \multicolumn{2}{c}{$\mathbf{1}^{\text {St }}$ region } & \multicolumn{2}{c}{$\mathbf{2}^{\text {nd }}$ region } & Final residue at \\
\cline { 2 - 6 } & Range $^{\circ} \mathbf{C}$ & Peak $^{*}{ }^{\circ} \mathbf{C}$ & Range $^{\circ} \mathbf{C}$ & Peak $^{*}{ }^{\circ} \mathbf{C}$ & $\mathbf{6 0 0}^{\circ} \mathbf{C}(\%)$ \\
\hline LO microcapsules & $180-285$ & 192 & $285-480$ & 381 & 4.67 \\
\hline LO P-microcapsules & $165-280$ & 178 & $280-505$ & 393 & 3.62 \\
\hline PPO microcapsules & $195-285$ & 201 & $285-475$ & 391 & 4.93 \\
\hline PPO P-microcapsules & $170-280$ & 183 & $280-520$ & 402 & 4.02 \\
\hline BSO microcapsules & $215-290$ & 220 & $290-490$ & 391 & 7.43 \\
\hline BSO P-microcapsules & $165-280$ & 180 & $280-525$ & 377 & 6.70 \\
\hline AO microcapsules & $190-290$ & 202 & $290-513$ & 386 & 10.9 \\
\hline AO P-microcapsules & $170-283$ & 187 & $283-590$ & 384 & 4.47 \\
\hline
\end{tabular}

* From derivative thermogravimetry (DTG) curve of all samples

The thermal degradation shows an overlapping temperature range of the core and shell materials which limits the accurate determination of the percentage of each component. This limitation led us to determine the percentages of encapsulated oils and polymeric materials used as shell materials for encapsulation via the solvent extraction method. Thus, a determined weighed mass $(\mathrm{m} 1)$ of each prepared microcapsule was mixed with $\mathrm{n}$-hexane and sonicated for 10 min. The suspension was filtrated, and the obtained solid filtrate was dried in an oven at $50^{\circ} \mathrm{C}$ until the generation of a constant weight (m2). The oil content of the microcapsules was then determined using the following equation (1):

The obtained results are summarized in the Table 2 .

$$
\text { Oil content }(\%)=\frac{(m 1-m 2)}{m 1} 100 \%(1)
$$

Table 2. Oil content of the prepared microcapsules.

\begin{tabular}{lcccccccc} 
Sample & LO MC & LO P-MC & PPO MC & PPO P-MC & BSO MC & BSO P-MC & AO MC & AO P-MC \\
\hline $\begin{array}{l}\text { Oil content } \\
(\%)\end{array}$ & 63.60 & 72.14 & 67.16 & 72.02 & 51.31 & 69.60 & 44.38 & 67.56 \\
\hline
\end{tabular}

It is worth to mention that the thermal degradation of the microcapsules resulted in a final residue higher in the case of MC compared to the P-MC for each encapsulated oil, this could be related to the oil content of the microcapsules. The TGA analysis reported the absence of the other materials used for the encapsulation, especially the SDS material usually characterized by a degradation temperature range between $162{ }^{\circ} \mathrm{C}$ and $218{ }^{\circ} \mathrm{C}$.

The flame retardancy aspect of the phosphorylated ethyl cellulose was clearly present for the obtained P-MC, the phosphorylated shell induced an early degradation due to the phosphorous groups on the microcapsules surface owing to the formation of a protective layer on the outer shell of the capsules. 


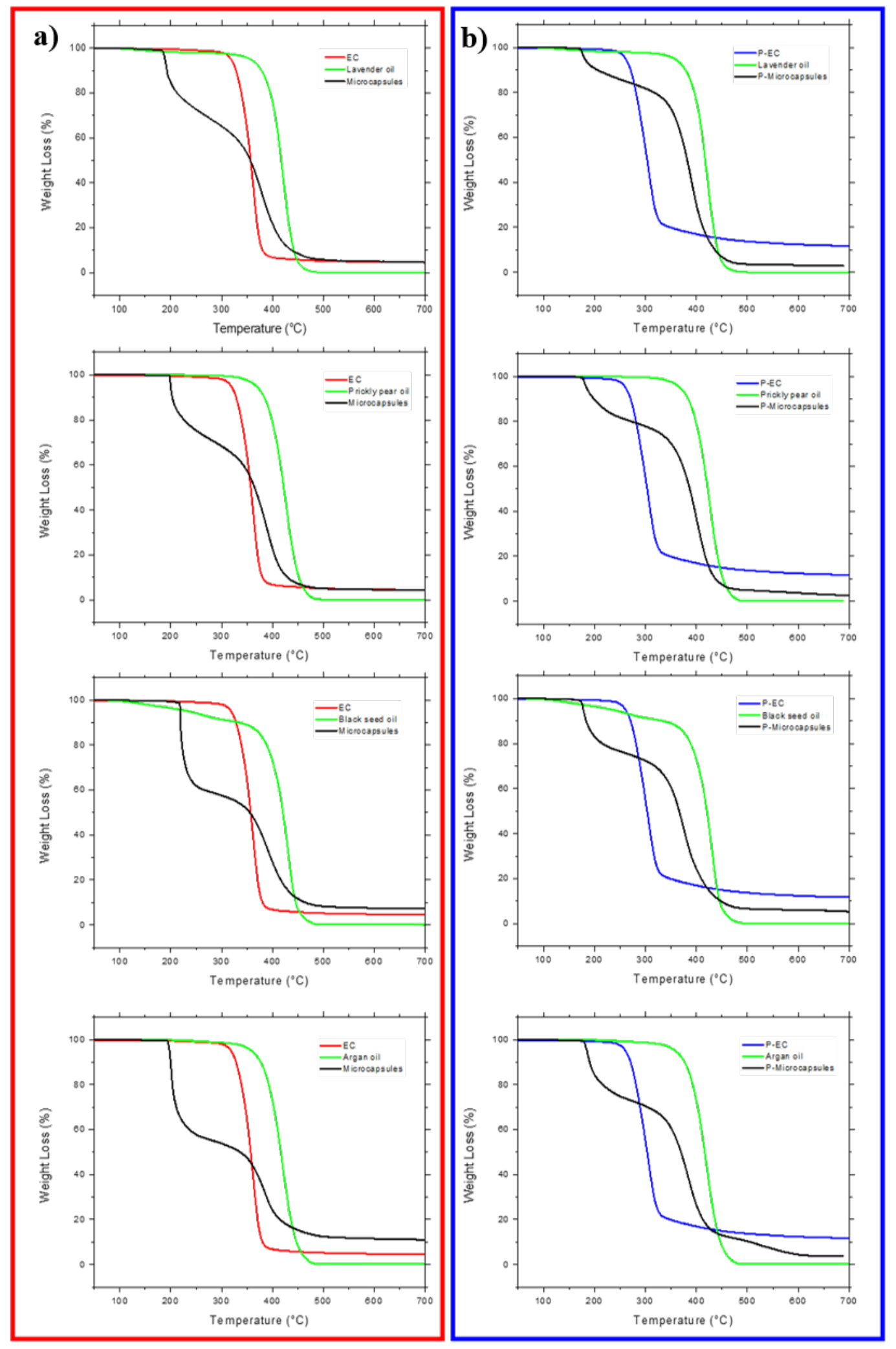

Fig. 2. (a) TGA weight loss curves of ethyl cellulose (EC), Lavender oil, Prickly pear oil, Black seed oil, Argan oil and the corresponding microcapsules. (b) TGA weight loss curves of phosphorylated ethyl cellulose (P-EC), Lavender oil, Prickly pear oil, Black seed oil, Argan oil and the corresponding P-Microcapsules. 


\subsection{Microcapsules morphology}

The morphology of the prepared oil-filled microcapsules was investigated by SEM. The obtained micrographs are illustrated in Fig. 3. It was clear shown that the obtained microcapsules are spherical in shape with some roughness and cavities on the surface which may induce a better compatibility effect with the coating matrix. The freeze drying performed as a last step in the microcapsule's preparation, could be the source of the observed cavities and some broken capsules as well. [14]

Expectedly, a micrometric size distribution of the generated capsules can be clearly observed from the micrographs in Fig. 3, indicating the efficiency of the preparation method using both crude ethyl cellulose and phosphorylated ethyl cellulose with four encapsulated oils (LO, PPO, BSO and AO remplace ces abreaviations,). Furthermore, the size distribution of the microcapsules was estimated from the micrographs to be in the range of $10 \mu \mathrm{m}$ to $170 \mu \mathrm{m}$.

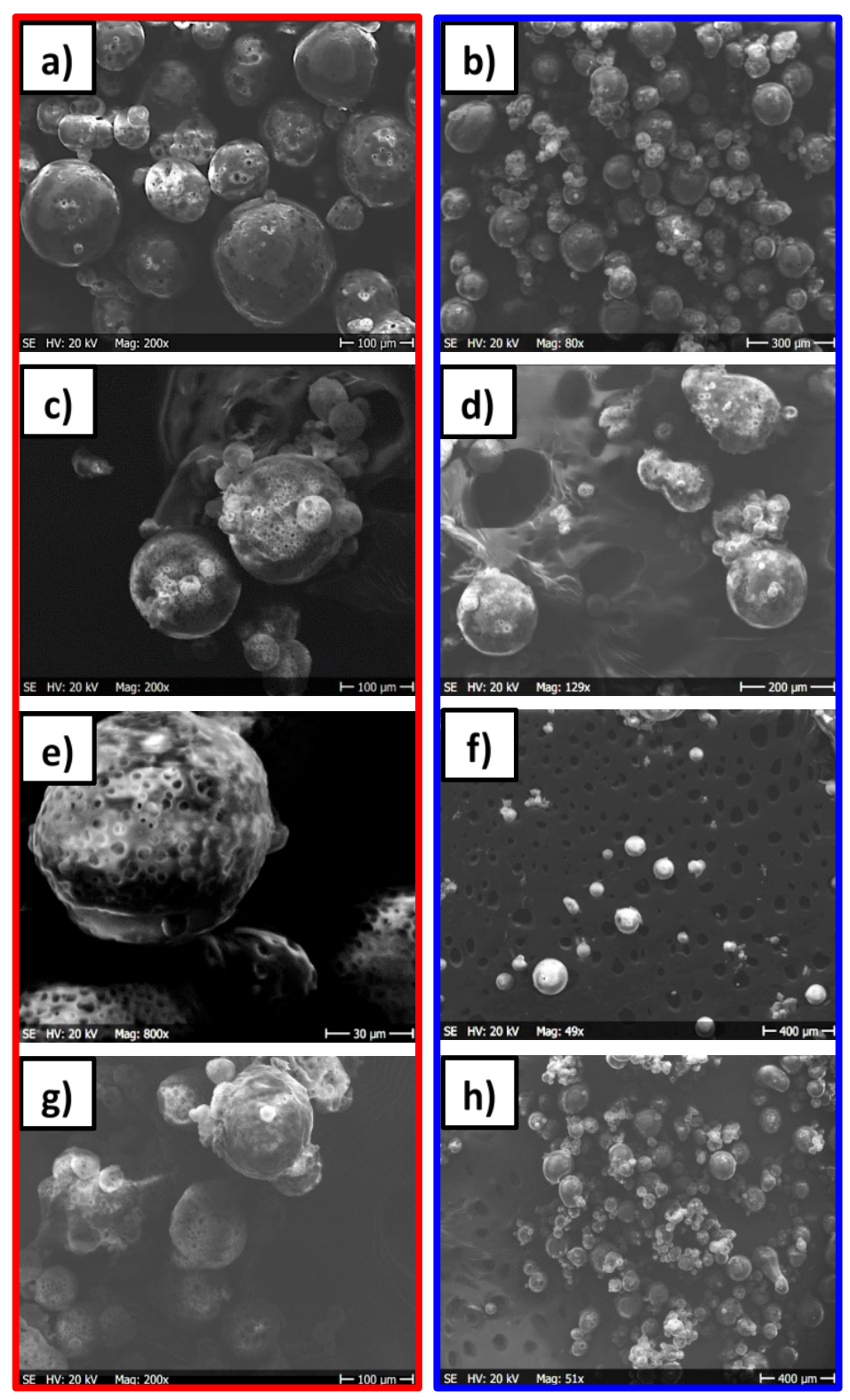

Fig. 3. SEM micrographs of oil-filled microcapsules using (a) LO and EC, (b) LO and P-EC, (c) PPO and EC, (d) PPO and P-EC, (e) BSO and $\mathrm{EC}$, (f) BSO and P-EC, (g) AO and EC, (h) AO and P-EC. (remplace ces abreaviations, trop) 


\section{Conclusions remplace les abreaviations,}

In this study, oil-filled microcapsules were successfully prepared via solvent evaporation method. crude ethyl cellulose and phosphorylated ethyl cellulose were used as polymeric shell materials to encapsulate four different oils (LO, PPO, BSO and AO remplace ces abreaviations,). As far as we know, this was the first time to encapsulate the abovementioned oils using a phosphorylated ethyl cellulose as a shell-forming polymer. The microcapsules composition was evaluated by FTIR, and the obtained results proved that the microcapsules were only composed from the oil core material (LO, PPO, BSO or AO) and the shell material (EC or P-EC remplace ces abreaviations,). TGA analysis was used to investigate the thermal stability of the microcapsules and it confirmed the flame-retardant aspect induced to the P$\mathrm{MC}$ through the use of P-EC as a shell material. The oil content was determined for the obtained microcapsules. More exploration of the oil's properties effect on the final capsules need to be investigated. The SEM micrographs further confirmed the efficiency of the preparation method and showed the spherical shape of the microcapsules with a particles size range of 10-170 $\mu \mathrm{m}$. The main objective of this study was to proof the concept of oil encapsulation using $\mathrm{P}-\mathrm{EC}$ as a shell, the prepared microcapsules will be destined for the preparation of anti-corrosion self-healing coatings.

\section{Acknowledgements}

The authors would like to thank the OCP foundation for the financial support through the doctoral program from Mohammed VI Polytechnic University.

\section{Conflict of interest}

The authors declare no conflict of interest.

\section{References}

[1] J. Gaitzsch, X. Huang, and B. Voit, "Engineering Functional Polymer Capsules toward Smart Nanoreactors," Chem. Rev., vol. 116, no. 3, pp. 1053-1093, Feb. 2016, doi: 10.1021/acs.chemrev.5b00241.

[2] L. Gasperini, J. F. Mano, and R. L. Reis, "Natural polymers for the microencapsulation of cells.," J. R. Soc. Interface, vol. 11, no. 100, p. 20140817, Nov. 2014, doi: 10.1098/rsif.2014.0817.

[3] X. Huang and B. Voit, "Progress on multi-compartment polymeric capsules," Polym. Chem., vol. 4, no. 3, pp. 435-443, 2013, doi: 10.1039/C2PY20636F.

[4] M. Peanparkdee, S. Iwamoto, and R. Yamauchi, "Microencapsulation: a Review of Applications in the Food and Pharmaceutical Industries," Rev. Agric. Sci., vol. 4, no. 0, pp. 56-65, 2016, doi: 10.7831/ras.4.56.

[5] R. P. Wool, "Self-healing materials: a review," Soft Matter, vol. 4, no. 3, pp. 400-418, 2008, doi: 10.1039/B711716G.

[6] S. R. White et al., “Autonomic healing of polymer composites.," Nature, vol. 409, no. 6822, pp. 794-797, Feb. 2001, doi: 10.1038/35057232.

[7] M. Behzadnasab, S. M. Mirabedini, M. Esfandeh, and R. R. Farnood, "Evaluation of corrosion performance of a self-healing epoxy-based coating containing linseed oil-filled microcapsules via electrochemical impedance spectroscopy," Prog. Org. Coatings, vol. 105, pp. 212-224, 2017, doi: https://doi.org/10.1016/j.porgcoat.2017.01.006.

[8] H. Li, Y. Cui, H. Wang, Y. Zhu, and B. Wang, "Preparation and application of polysulfone microcapsules containing tung oil in self-healing and self-lubricating epoxy coating," Colloids Surfaces A Physicochem. Eng. Asp., vol. 518, pp. 181-187, 2017, doi: https://doi.org/10.1016/j.colsurfa.2017.01.046.

[9] B. N. Estevinho and F. Rocha, "Chapter 7 - Application of Biopolymers in Microencapsulation Processes," in Handbook of Food Bioengineering, A. M. Grumezescu and A. M. B. T.-B. for F. D. Holban, Eds. Academic Press, 2018, pp. 191-222.

[10] A. Ouarga, H. Noukrati, I. Iraola-Arregui, A. Elaissari, A. Barroug, and H. Ben youcef, "Development of anti-corrosion coating based on phosphorylated ethyl cellulose microcapsules," Prog. Org. Coatings, vol. 148, p. 105885, 2020, doi: https://doi.org/10.1016/j.porgcoat.2020.105885.

[11] S. M. Mirabedini, I. Dutil, and R. R. Farnood, "Preparation and characterization of ethyl cellulose-based core-shell microcapsules containing plant oils," Colloids Surfaces A Physicochem. Eng. Asp., vol. 394, pp. 74-84, 2012, doi: https://doi.org/10.1016/j.colsurfa.2011.11.028.

[12] D. Predoi et al., "Properties of Basil and Lavender Essential Oils Adsorbed on the Surface of Hydroxyapatite," Materials, vol. 11, no. 5. 2018, doi: 10.3390/ma11050652.

[13] M. Villa Nova et al., "Formulation and characterization of ethylcellulose microparticles containing .1-alanyl- 
l-glutamine peptide," Drug Dev. Ind. Pharm., vol. 40, no. 10, pp. 1308-1317, Oct. 2014, doi: 10.3109/03639045.2013.817417.

[14] S. Ray, U. Raychaudhuri, and R. Chakraborty, "An overview of encapsulation of active compounds used in food products by drying technology," Food Biosci., vol. 13, pp. 76-83, 2016, doi: https://doi.org/10.1016/j.fbio.2015.12.009. 